\title{
A bicicleta como resistência: o paradigma rodoviarista e o papel do ativismo ciclista no município de São Paulo/SP
}

\author{
Bicycles as resistance: the road paradigm \\ and the role of cyclist activism in São Paulo/SP
}

Lucas Bravo Rosin [l]

Cristiane Kerches da Silva Leite [II]

\begin{abstract}
Resumo
Discute-se a formação da agenda de ciclomobilidade em São Paulo/SP enquanto um processo de resistência na configuração do espaço urbano, com raízes profundas e longevas no paradigma rodoviarista, na mercantilização do território, em contexto neoliberal. Por meio de pesquisa qualitativa que articula dados secundários e primários, argumenta-se que, em São Paulo, há movimentos de resistência ao processo de apropriação privada do espaço urbano no campo da mobilidade. Conclui-se que o ciclo-ativismo tem cumprido um papel importante na circulação de ideias de resistência e no tensionamento do paradigma rodoviarista, sendo um dos elementos que explicam a inserção da bicicleta na cidade, além do ciclo de manifestações de 2013 e a eleição de Fernando Haddad à prefeitura.
\end{abstract}

Palavras-chave: política pública; mobilidade urbana; bicicleta, resistência; ativismo urbano.

\begin{abstract}
In this paper, we discuss the inclusion of cycling in the mobility agenda of the city of São Paulo as a resistance process in the configuration of the urban space, which is characterized by the road paradigm and the commodification of the territory, in a neoliberal context. Through a qualitative research, which articulates secondary and primary data, we argue that, in São Paulo, there are resistance movements against the private appropriation of the urban space in the field of mobility. We conclude that cyclist activism has played an important role in the circulation of resistance ideas and in tensioning the road paradigm, being one of the elements that explain the insertion of the bicycle in the city, besides the 2013 protests and the election of Fernando Haddad to the City Hall.
\end{abstract}

Keywords: public policy; urban mobility; bicycle; resistance; urban activism. 


\section{Introdução}

A perspectiva histórica sobre a mobilidade urbana no Brasil permite verificar dinâmicas de conflito e disputa entre interesses e paradigmas distintos. 0 conflito entre a lógica da democratização e do planejamento público do território e a lógica da mercantilização e da segregação espacial é anterior ao período de acumulação pós-fordista e ao processo de financeirização. Há raízes históricas profundas no processo de mercantilização dos espaços urbanos que explicam as inércias e os limites dos vetores de mudança em curso.

Os veículos automotores são, inegavelmente, um dos principais símbolos do deslocamento nas cidades, sobretudo nas de grande porte, desde a era fordista (Harvey, 2014). Na América Latina, em geral, a produção automobilística foi a principal marca do desenvolvimento regional da segunda metade do século XX (Vasconcellos, 2013), influenciando a estruturação e a consolidação de estados nacionais no continente (Hobsbawn, 2007). No Brasil, em particular, a convergência entre o automóvel e o planejamento urbano configurou-se, durante muitos anos, como o "casamento do século" (Lara, 2016).

Em termos coletivos, o automóvel foi caracterizado como eixo modal central no planejamento urbano moderno. As grandes cidades brasileiras, projetadas e remodeladas ao longo do século $\mathrm{XX}$, seguiram a cartilha dos arquitetos e urbanistas alinhados aos princípios da "Carta de Atenas" de 1933, na qual o carro servia de conector entre os diversos setores planejados em função das demandas do mercado (Lara, 2016; Tavolari, 2016). Como resultado, formou-se uma ampla coalizão de interesses políticos e econômicos em torno da cadeia produtiva do automóvel, assim como se consolidou sociologicamente a ideia de que o uso do carro é um signo social de êxito. Reificado como solução acabada para os deslocamentos urbanos, esse meio de transporte configurou-se em um símbolo inequívoco do tipo de modernização e dos padrões contemporâneos de relações sociais nas sociedades capitalistas democráticas, individualistas e mercadorizantes (Schor, 1999).

Diante dos grandes interesses organizados e do sentimento público (Campbell, 1998) amplamente consolidado, o consenso em torno do paradigma rodoviarista na interpretação dos problemas relativos aos transportes urbanos e a posterior construção de soluções entre atores governamentais foram uma decorrência inequívoca (Vasconcellos, 2013; Rolnik e Klintowitz, 2011; Lara, 2016; Requena, 2015). A ideia de usar a bicicleta como meio de transporte urbano, sobretudo em grandes centros, surgiu e foi sendo discutida em contextos político-institucionais marcados pela hegemonia automobilística, inclusive no plano internacional, elevando de forma exponencial o custo da possibilidade de mudanças futuras. Assim, argumenta-se que a agenda cicloviária é um elemento em um quadro complexo, configurado por grandes interesses historicamente constituídos, mas que tem assumido papel de resistência: a partir de um longo processo de aprendizagem social (Hall, 1993) e de mudança de imagem (Baumgartner e Jones, 1993), a bicicleta tem tensionado o monopólio de ideias sobre políticas públicas de mobilidade urbana centrada no modal rodoviarista, no contexto da ordem neoliberal. ${ }^{1}$ 
Este trabalho discute a trajetória histórica da hegemonia rodoviarista no planejamento urbano paulistano e como, a despeito desse legado, novos atores políticos e sociais, redes e comunidades articularam-se e foram determinantes para a ascensão de uma agenda alternativa voltada para os deslocamentos urbanos em bicicleta. Considerando o município de São Paulo como microcosmo desse processo, verifica-se claramente a hegemonia de dinâmicas de apropriação privada e captura dos espaços públicos configurados pelo paradigma rodoviarista, tendo o automóvel como eixo do processo de construção da cidade. Historicamente, coalizões automobilísticas organizadas em escala global influenciaram a tomada de decisão de atores políticos governamentais no município. Nos anos 1920, o governo de Washington Luís tinha como lema "Governar é abrir estradas". Em seguida, Prestes Maia, com seu "Plano de avenidas", cortou a cidade com vias radiais e marginais. Na mesma linhagem política e urbanística, Paulo Salim Maluf e Jânio Quadros deixaram como legado vultosas obras viárias, marcadas por viadutos e túneis. ${ }^{2}$

Em São Paulo, a despeito das raízes profundas e longevas do paradigma rodoviarista, há movimentos de resistência no processo de apropriação privada do espaço urbano no campo da mobilidade. Argumenta-se que o ativismo político ligado aos ciclistas tem cumprido um papel importante nos últimos anos na circulação de ideias de resistência e no tensionamento do paradigma rodoviarista. Trata-se, também, de um movimento internacional, que se expressa no caso do município, caracterizado pela produção de conhecimento e experiências cicloviárias exitosas em países do Norte, disseminados por atores em redes e comunidades de políticas públicas (Massardier, 2006), muitas vezes sem as formalidades da cooperação internacional interinstitucional.

$\mathrm{Na}$ perspectiva de analisar um caso de construção política de resistência, avalia-se, neste texto, o processo de construção da agenda governamental cicloviária em São Paulo, com destaque para a atuação do ativismo cicloviário. Argumenta-se que os ativistas agiram como comunidade epistêmica (Haas, 1992) dentro de secretarias de estado do município, desempenhando um papel político de defesa da ideia da bicicleta como meio de transporte viável. As estratégias de ação configuraram-se dentro e fora da máquina pública e foram conectadas a redes internacionais. 0 processo político que se propõe a analisar, neste texto, gerou as bases políticas e institucionais para a implementação da agenda cicloviária em São Paulo, precisamente no governo Fernando Haddad (Partido dos Trabalhadores, no período de 2013-2016).

Articulam-se, analiticamente, três dimensões explicativas do processo de configuração da agenda de ciclomobilidade em São Paulo: a dimensão da circulação de ideias e ressignificações da bicicleta no espaço urbano, levadas a cabo pelos movimentos ativistas; a dimensão contextual da contingência histórica propícia que se formou diante do ciclo de protestos de 2013 e da eleição de Fernando Haddad; e, por fim, a dimensão do processo político decisório que envolveu a pressão dos grupos ligados aos movimentos ativistas e as dinâmicas políticas decisórias dentro do novo governo municipal à época, disponível para dialogar com movimentos sociais e permeável à ideia de "direito à cidade". ${ }^{3}$ De forma interdependente, esses três elementos se destacam no aproveitamento da 
janela de oportunidade para mudança, propiciando a canalização política e institucional de forças de resistência, na perspectiva teórica da formação de agenda de Kingdon (2003).

Em termos metodológicos, utiliza-se o process tracing ${ }^{4}$ (Beach e Pedersen, 2013; Cunha e Araújo, 2018) como método qualitativo de estudo de caso, orientando a coleta e análise dos dados secundários e primários. 0 process tracing é um método de estudo de caso focado na compreensão sobre a causalidade qualitativa dos processos sociais. A técnica caracteriza-se pela ampla descrição histórica e também pela força das inferências que produz a partir da triangulação de informações e evidências. Neste trabalho, optamos por utilizar a variação do método outcome explaining, epistemologicamente centrada no caso, que permite trabalhar de forma flexível e articulada com modelos teóricos complementares.

Trabalha-se com análise de dados secundários em perspectiva macro-histórica (Reis, 2015). A partir de estudos produzidos sobre as políticas de transportes e mobilidade urbana, em geral, e da ciclomobilidade urbana, em específico, elabora-se a trajetória da agenda cicloviária, tendo os subsistemas de políticas públicas como unidade de análise e enfatizando o papel dos atores vinculados aos movimentos ciclistas. Além disso, utilizam-se dados primários coletados em entrevistas semiestruturadas com atores que participaram do processo em análise, privilegiando fontes vinculadas à sociedade civil para explorar, complementar e triangular as inferências descritivas e causais.

Diante da inexistência de estudos sobre o processo de construção da agenda cicloviária em São Paulo, as entrevistas tiveram um papel destacado enquanto dados primários.
Em sintonia com o process tracing, as entrevistas semiestruturadas foram pensadas e adaptadas ao longo da pesquisa, a partir da análise de dados secundários (como documentos oficiais, material de imprensa e informações sobre os entrevistados). De forma ampla, as entrevistas foram realizadas com os objetivos: explorar o processo buscando informações inéditas sobre a sequência de eventos que levaram ao resultado observado (a construção de uma rede cicloviária); delimitar as fronteiras da rede de atores envolvidos de forma mais direta com o processo, ajudando a identificar novos atores relevantes por meio da técnica de "bola de neve"; identificar as crenças e as ideias que pautaram a ação coordenada dos arranjos interacionais; triangular evidências observadas em dados secundários e primários para construir inferências mais robustas. ${ }^{5}$

Além desta introdução, este texto está organizado nas seguintes seções: teórica (abordando a sociologia macro-histórica e modelos de políticas públicas mobilizados neste trabaIho); aspectos da gênese, apogeu e crise do paradigma rodoviarista no Brasil; trajetória da participação social no processo de construção da agenda cicloviária e, por fim, as considerações finais.

\section{Da sociologia macro-histórica aos modelos de políticas públicas: atores, arranjos interacionais, ideias e contextos}

Nesta pesquisa, trabalha-se com o pressuposto teórico da sociologia macro-histórica, 
entendendo que dinâmicas de disputa e conflito entre atores públicos e privados marcaram a sociogênese das estruturas políticas e institucionais (Elias, 1993). Na história do desenvolvimento social, o aumento da complexidade nos laços de interdependência promove a passagem do monopólio privado para o público. Esse processo se expressa em um "mecanismo monopolista" geral, comum a todos os Estados modernos, concentrados no controle do poder coercitivo articulado com o poder de tributar renda e propriedade. Nesse processo, a interpretação dos problemas públicos é central para compreender a expansão das responsabilidades dos Estados e o processo de espraiamento territorial do monopólio estatal, aspecto fundamental na configuração dos Estados modernos (ibid., p. 107).

Seguindo a trilha de Norbert Elias na análise do desenvolvimento social, Polanyi (2000) desnuda os processos políticos e sociais que estão na base da ideia de mercado, ou seja, os pressupostos do espraiamento da lógica da mercantilização dos espaços sociais. Não se trata de uma estrutura natural, mas originada de relações sociais reguladas pelo Estado. 0 autor demonstra que somente houve a expansão da lógica do mercado nos espaços sociais mediante a criação de mecanismos protetores, tanto da sociedade como do próprio capital. Os mecanismos da sociedade buscam resguardar a substância humana por meio de instituições protetoras (como leis, normas, serviços públicos, etc.), enquanto as proteções ao capital (subsídios, regulamentações, etc.) protegem os interesses de mercado das incertezas da própria lógica de mercantilização. Essa relação contraditória se expressaria na dualidade sociedade versus Mercado, tendo o Estado como fiador dessa relação, oscilando entre as duas forças sociais, embora a história tenha mostrado maior proximidade dos Estados modernos com os interesses do Mercado (Polanyi-Levitt, 2014).

Schneider e Escher (2011) argumentam que na obra de Polanyi há uma agenda de pesquisa essencial no atual contexto histórico de financeirização das relações sociais e de espraiamento da lógica da cidade-mercadoria na produção de espaços urbanos em escala global. São quatro grandes temas: a mercantilização de questões sociais; a natureza do mercado e sua relação com a noção de embeddedness; a coexistência de formas distintas de integração econômica nas sociedades capitalistas e suas relações com o papel do Estado e das políticas públicas; o papel dos atores da sociedade civil e das instituições nos processos de mudança social. A partir desse esquema de análise, que permite "apreender de forma dinâmica e histórica as inter-relações entre Estado, mercados e sociedade civil" (ibid., p. 214), a escolha de categorias analíticas operacionais no campo das políticas públicas permeou autores que articulam ideias, interesses, atores individuais e coletivos, instituições e contextos de incerteza, conflito e dissenso, na análise de mudanças e inércias políticas. São autores que seguem a orientação pós-positivista de políticas públicas e articulam elementos cognitivos. ${ }^{6}$

Três modelos foram fontes de categorias analíticas mobilizadas de forma pontual na análise deste trabalho: o de Múltiplos Fluxos, de John Kingdon (2003), o de Equilíbrio Pontuado, de John Baumgartner e Brian Jones (1993), e o modelo de Coalizões de Defesas, de Paul Sabatier (1988). 
Ao questionar "quando chega a hora de uma ideia?", Kingdon (2003) busca entender como determinadas questões ganham atenção na agenda do governo e por que algumas decisões são tomadas em detrimento de outras. Como ocorrem as mudanças nas agendas de políticas públicas nas democracias contemporâneas? Em seu modelo explicativo de múltiplos fluxos, o autor articula o fluxo de problemas (a dimensão interpretativa dos governos que seleciona, da multiplicidade de questões no mundo, os problemas a serem tratados como objeto de política pública); o fluxo de soluções (o processo de disputa de diferentes ideias paradigmáticas - ou concepções sociais basilares de políticas - para configurar uma política pública); e o fluxo político (os processos de disputa e barganha que movimentam as políticas públicas, a partir de pressão de grupos organizados e/ou mudanças de governo). $\mathrm{Na}$ articulação interdependente desses três fluxos de fenômenos, o autor valoriza o papel de empreendedores e comunidades reunidas em torno de determinadas ideias de políticas públicas. Ainda que não seja condição suficiente para a geração de novas soluções a serem assimiladas pela agenda governamental, as comunidades de políticas públicas configuram um espaço privilegiado de experimentação, debate, difusão de ideias e formação de redes. Para Baumgartner e Jones (1993), a abordagem do "equilíbrio pontuado" tem, como centro, a ideia de monopólio de políticas sobre determinado assunto público, ou seja, um significado de política que se pereniza no tempo, de forma inercial. Tal monopólio se manteria graças à coesão dos membros do subsistema que domina um assunto em termos de entendimento sobre determinada política, a imagem da política, além das estruturas institucionais, que limitam o acesso de novos atores ao processo decisório.

Finalmente, o "modelo de coalizões de defesa" articula conceitos importantes dos modelos anteriores. No subsistema de políticas, ocorrem as disputas polarizadas entre coalizões de defesa, que se organizam internamente a partir de um "sistema de crenças". 0 "amálgama" entre os atores e grupos de uma coalizão envolve: o núcleo duro, o nível das crenças e valores fundamentais; o núcleo político, que diz respeito às estruturas normativas e cognitivas; e o nível instrumental (aspectos secundários), que diz respeito às ideias técnicas e operacionais (Tomazini e Leite, 2016). Os subsistemas sofrem influências externas, que podem orientar as ações das coalizões de defesa, como no caso do subsistema da mobilidade urbana em São Paulo e da coalizão em torno da bicicleta. Considera-se que os movimentos ativistas em defesa da bicicleta, componentes dessa coalizão, defenderam o paradigma cicloviário de política de mobilidade (Hall, 1993) e acumularam, no tempo, um processo de aprendizagem social (ibid.), ou seja, ajustaram deliberadamente metas, objetivos e técnicas em resposta a experiências passadas e novas informações, com o intuito de promover suas ideias às políticas públicas (Leite e Peres, 2015, p. 626).

Os atores políticos e sociais que participam do processo de construção de políticas públicas constroem vínculos em comunidades, redes e subsistemas temáticos (Massardier, 2006). Esses "arranjos interacionais" são propulsores da difusão de ideias e da busca de construção de consensos sobre políticas, mas também se estruturam em torno destas. As comunidades são mais coesas e fechadas, enquanto as redes temáticas são mais 
heterogêneas e participativas. Vale ressaltar que o conceito de redes é mais amplo e vem sendo trabalhado no campo das ciências sociais no Brasil. 0 conceito é definido, de forma geral, como "o tecido das relações entre indivíduos, grupos e entidades nas sociedades, estruturando os campos nos quais os fenômenos sociais acontecem" (Marques, 2012, p. 8). Agregando os arranjos anteriores, a ideia de subsistema de política consiste numa arena decisória "composta por um número limitado de atores e instituições, reunidos em grupos mais ou menos coesos, que se especializam e direcionam esforços para algumas questões específicas em relação a uma política" (Capella e Brasil, 2015, p. 58).

Argumenta-se, dessa forma, que as pontes propostas neste trabalho entre a sociologia macro-histórica e as políticas públicas são caminhos profícuos para a análise de questões relacionadas à "mercantilização dos problemas públicos" e à "construção de mecanismos de resistência em contexto de globalização neoliberal via redes entre atores sociais e políticos". Propõe-se, neste trabalho, uma análise multinível de médio alcance (mezzo). Em mobilidade urbana, o domínio do carro penetra tanto no imaginário coletivo de soluções para os deslocamentos urbanos, como nas cadeias econômicas e arranjos políticos de representação em instituições políticas. A bicicleta, nessa perspectiva, carrega um potencial de resistência diante de grandes interesses, na disputa pela configuração do espaço urbano de São Paulo como cidade-mercadoria que convive com contradições e complexidades relacionadas ao arcabouço do direito à cidade, por exemplo.

\section{Aspectos da gênese, apogeu e crise do paradigma rodoviarista no Brasil}

É consenso, na literatura, que o planejamento urbano brasileiro foi marcado pela centralidade do automóvel como elemento de mobilidade (Vasconcellos, 2013; Lara, 2016), constituindo-se como paradigma de políticas de mobilidade urbana (Rolnik e Klintowitz, 2011; Requena, 2015; Leite, Cruz e Rosin, 2018). Segundo Lara (2016), a relação "identitária" entre a sociedade brasileira e os automóveis remonta à primeira metade do século XX. Aproximadamente, 95\% dos domicílios brasileiros foram construídos após 1940, período no qual ocorreu o "casamento" entre o processo de urbanização (de corte modernista) e o automóvel.

0 período que compreende os anos 1920 e 1950 seria marcado pela disputa entre projetos urbanos locais de caráter "ecológico" e projetos rodoviaristas. Tal como a disputa travada em São Paulo entre o engenheiro sanitarista Saturnino de Brito e o rodoviarista Prestes Maia, vencida por este último, anteriormente, outras disputas semelhantes ocorreram em cidades importantes. No Rio de Janeiro, o projeto do também sanitarista André Rebouças, que propunha uma expansão em sintonia com as características naturais da cidade, foi derrotado pelo projeto de Francisco Pereira Passos que, assim como Prestes Maia, executou seu plano de avenidas como prefeito do respectivo município. 0 modelo que inspirou o "plano de avenidas" tem raízes nas reformas urbanas de Georges-Eugène Haussmann, prefeito de Paris 
entre 1853 e 1870 . Pautado nas discussões da época sobre a modernidade e o desenvolvimento da mobilidade, da rapidez e da comodidade dos deslocamentos, Haussmann construiu bulevares e ruas largas, visando a melhorar 0 fluxo de pessoas e mercadorias. Ainda que 0 carro não houvesse se consolidado de forma massiva, Paris já havia preparado as bases para se lançar como cidade mais preparada para receber a lógica do automóvel. Entre o final do século XIX e as primeiras décadas do século $X X$, houve uma revolução na indústria automobilística, sobretudo a partir do "fordismo", que configurou relações e estruturas econômicas, sociais, culturais e políticas em escala global. A Carta de Atenas, que absorveu diversas ideias dos manifestos futuristas, confirmaria a influência do automóvel, marcando sua hegemonia no bojo do urbanismo nascente que pautaria a organização das sociedades urbanas do século XX (ibid.).

A cidade de Belo Horizonte foi palco de um importante momento da trajetória do paradigma rodoviarista no Brasil. Quando Juscelino Kubitschek (JK) chegou à prefeitura de BH, nos anos 1940, teve que se relacionar com investidores privados que trabalhavam junto ao poder público no processo de urbanização. 0 diagnóstico do prefeito apontou para dificuldades de conexão e integração com a malha urbana. As ações propostas como solução, então, visaram a inserir a região na malha viária por meio da construção de uma avenida ligando a Pampulha ao norte da cidade. Ainda, e mais importante, JK buscou se associar ao proeminente arquiteto modernista à época, Oscar Niemeyer, que projetou diversos equipamentos públicos e privados que foram construídos no local. Essa parceria foi responsável pela inserção do carro na dinâmica urbana (ibid.) ou, nos termos de Polanyi (2000), por "enraizar" o carro no imaginário cultural e político.

A ênfase de JK na indústria automobilística estava relacionada com seus ideais privatistas e desenvolvimentistas. 0 impacto significativo desse setor na cadeia de produção nacional bem com sua forte associação com a ideia de modernidade seriam os alicerces desse pensamento. Nesse sentido, a construção de Brasília foi uma "meta síntese da proposta de modernidade conservadora, sendo a cidade do automóvel por excelência". Segundo Lara (ibid., p. 140), para compreender a imagem construída entre o urbanismo e o carro, que criou um monopólio de ideias e interesses, é preciso "entender Brasília e todo o urbanismo brasileiro do século XX como uma grande apologia ao automóvel, que representa a máquina hegemônica na construção da mobilidade".

Nessa perspectiva, Brasília é produto de um processo em curso no País desde a primeira metade do século XX. Vasconcellos (2013) mostra com detalhes a centralidade da opção pelos transportes automotores nas políticas públicas de mobilidade urbana ao longo desse período histórico, dividindo-as entre as políticas de transporte e as de infraestrutura. Nos anos 1970, deflagrou-se um contexto de múltiplas crises. Em primeiro lugar, o processo de urbanização brasileiro alcançava percentuais inéditos, tornando a realidade nacional majoritariamente urbana, concentrada em cidades de grande e médio porte. Além disso, a crise internacional do petróleo agregou novos elementos que induziram a entrada do governo federal no tema, tanto no planejamento urbano como na área de projetos de sistemas de transportes coletivos. Diante da explosão da urbanização e da 
importância estratégica da indústria automobilística na economia nacional, o governo federal se pautou na dependência do ônibus como principal vetor dos transportes coletivos. Nesse sentido, o governo militar criou um ambiente propício para investimento do setor, articulado com uma nova institucionalidade.

Em 1975, foi estabelecido o Sistema Nacional de Transportes Urbanos, que previa a criação da Empresa Brasileira de Transportes Urbanos (EBTU) em nível nacional, e das Empresas Metropolitanas (EMTUs) em nível regional (Xavier, 2011; Vasconcellos, 2013). A criação desse sistema institucionalizou o subsistema das políticas de transporte urbano, que foi base para 0 atual subsistema de mobilidade urbana. Naquele momento, foi constituída uma "grande empresa de ônibus", composta por algumas organizações privadas que operavam nos sistemas de transportes coletivos e seriam atores relevantes na proposição de soluções para o tema dos transportes urbanos durante o período.

A Constituição Federal de 1988 pode ser interpretada como um contramovimento democrático, nos termos polanyianos, com relação à história de exclusão e segregação em várias áreas sociais. A participação social passou a ser compreendida como um imperativo organizativo, abrindo espaço para atores e organizações sociais outrora alijados das arenas de formulação de políticas públicas (Milani, 2008).

A Carta Magna também criou uma série de regulamentações que propunham a restrição de espaços de liberdade de atores privados, inclusive na área de transporte e mobilidade urbana, na linha do que Polanyi define como proteções sociais. No entanto, logo no início dos anos 1990, o contra-ataque dos interesses privados organizou-se com a ampliação da mercantilização do transporte. Naquele período de liberalização da economia, ocorreu a introdução da motocicleta no mercado brasileiro, de forma desregulada e que iniciaria um processo com resultados catastróficos no final dos anos 2010. Se, em 1990, 123.169 motocicletas foram vendidas no País, em 2011 esse número saltou para mais de dois milhões. 0 desastre social seguiu a tendência: segundo os números do DPVAT, as fatalidades que envolvem motocicletas subiram de 7.624, em 1966, para 176.902 em 2012. Para além da moto, o consumo de veículos automotores foi estimulado por diversas medidas, ao longo dos anos 2000, como a criação da Cide, em 2001, e o "IPI 0" como resposta contracíclica às crises econômicas mundiais em 2008 (Vasconcellos, 2013, pp. 80-95).

Um olhar sobre o processo histórico que constitui o subsistema de políticas de mobilidade urbana mostra como o transporte individual motorizado prevaleceu sobre as formas ativas, alternativas e coletivas de transporte. Contudo, a aposta nos transportes motorizados, em especial os veículos individuais, trouxe resultados desastrosos, tanto no Brasil como no mundo, que "decretaram a morte teórica" do paradigma rodoviarista. Muitas evidências empíricas apontam para a incapacidade dos veículos automotores individuais em solucionar o problema dos deslocamentos urbanos (ONU Habitat, 2017). Trata-se de um monopólio de políticas (Baumgartner e Jones, 1993), mas que tem sido crescentemente tensionado ou, nos termos de Kingdon (2003), sofrido feedbacks negativos que têm aberto brechas de apoio à inserção de novas correntes ideacionais e grupos de interesses nas arenas de políticas públicas. Dessa forma, novos paradigmas de políticas públicas 
passaram a compor, paulatinamente até os anos 1990, a agenda de transportes urbanos. Como exposto, esses processos são marcados por uma complexa interação entre atores internos e externos às instituições públicas.

A seguir analisaremos a trajetória da agenda cicloviária no município de São Paulo a partir da relação entre esses atores, com foco nas mudanças na participação da sociedade civil e movimentos ativistas nesse processo ao longo do tempo.

\section{A trajetória da participação social no processo de formaçãa e consolidação da agenda cicloviária: da capacidade relacional ao ativismo institucional}

0 processo de transformação do subsistema de mobilidade urbana em São Paulo foi marcado significativamente pelo movimento de uma rede de especialistas e ativistas de ciclomobilidade urbana. Nos termos de Massardier (2006) e Haas (1992), se seguirmos a trilha das ideias e dos interesses em torno das bicicletas em São Paulo, observamos atores oriundos de comunidades políticas e epistêmicas que circularam fora das instituições governamentais, mas que foram gradativamente penetrando nas arenas governamentais até chegarem às arenas decisionais. A partir de uma perspectiva histórica, argumenta-se que é possível analisar a atuação da sociedade civil a partir de três dimensões: quem está presente, como atua e quais são seus vínculos. Partindo dessas dimensões, pode-se identificar quatro gerações ${ }^{7}$ que vão se conectar e compartilhar conhecimentos, aprendizados, experiências e redes, ganhando legitimidade e ampliando seu poder de influência na mesma medida em que vai atraindo novos participantes e posições institucionais, em organizações tanto públicas como privadas.

A primeira geração surge e consolida-se ao longo dos anos 1980 e se divide em quatro agrupamentos. Em primeiro lugar, destaca-se o ativismo de Arturo Alcorta, bike repórter durante muitos anos, que transitava entre grupos políticos ligados ao governo de Franco Montoro (Partido do Movimento Democrático Brasileiro - PMDB,1983-1987), onde se aproximou de Walter Feldman, ${ }^{8}$ vereador eleito pelo Partido da Social Democracia Brasileira (PSDB), (E1)..$^{9} 0$ segundo grupo possui origens na Baixada Santista e se formou a partir das conexões entre o então Diretor Ambiental de uma indústria química de Cubatão, Gunther Bantel, e o Consultor Werner Zulauff, primeiro Secretário do Verde e do Meio Ambiente do município de São Paulo, instituição inaugurada na gestão municipal de Paulo Maluf, ${ }^{10}$ que convidaria Bantel para trabalhar de forma pioneira com a questão cicloviária, coordenando o Grupo Ciclista em 1993 (E3). 0 terceiro grupo organizou-se em torno das ações de Renata Falzoni, que começou a militar pelo ciclismo urbano, incorporando a pauta da luta pela igualdade de gênero. Além da militância pessoal, Falzoni transitava entre grupos sociais da elite paulistana, por meio de seus trabalhos nos meios de comunicação, mas também fundando e organizando as ações do night bikers club, como as "bikepasseatas", que reuniam pessoas interessadas e buscavam trazer visibilidade para a questão cicloviária, ainda que 
de forma incipiente (E7). Finalmente, o quarto grupo reunia especialistas técnicos, sobretudo engenheiros, que trabalhavam com transportes em instituições públicas, mas que também buscavam defender a questão cicloviária na Associação Nacional dos Transportes Públicos. Esse grupo tinha atores da comunidade epistêmica, como Sergio Bianco e Reginaldo Paiva, entre outros, que produziram importantes bases conceituais e técnicas para a formulação da agenda cicloviária (E11).

As primeiras iniciativas legislativas municipais mais consistentes em prol da construção de infraestrutura cicloviária surgem na capital paulistana no começo dos anos 1990. Destaca-se a atuação de Walter Feldman, responsável pelos projetos mais relevantes do período. As iniciativas foram mais simbólicas do que objetivas, uma vez que não produziram efeitos práticos de curto prazo. No entanto, pode-se dizer que a criação dessas leis provocou uma demanda que culminaria nos primeiros grupos de trabalho institucionais da prefeitura. Em 1993, a questão ganharia um espaço privilegiado no poder executivo municipal, que foi responsável por desenvolver a questão até meados dos anos 2000, demandando ações de outras instituições municipais, como a Companhia de Engenharia de Tráfego (CET) e a Secretaria Municipal dos Transportes (SMT) (E12).

No bojo da criação da Secretária do Verde e do Meio Ambiente (SVMA), que surgia em meio às repercussões da Conferência "Rio 92", foi constituído o Projeto Ciclista, grupo executivo que trabalhava a inserção da bicicleta na agenda governamental a partir da perspectiva ambiental. Em tal espaço foram gestadas as bases, sobretudo no que diz respeito às vias estruturais de alta complexidade, do sistema cicloviário que seria construído entre 2013 e 2016, e também a rede temática de política pública que fortaleceria o surgimento de grupos cicloativistas organizados e articulados (Leite, Cruz e Rosin, 2018). A partir da criação da Secretária do Verde e do Meio Ambiente em 1993, representantes desses grupos passaram a se encontrar nas discussões do grupo ciclista, responsável por tentar levar a cabo a agenda de políticas de mobilidade urbana em bicicleta (E3; E6; E8). Ali se formaria a segunda geração do cicloativismo, que uniu participantes da geração anterior com funcionários de carreira do município, interessados pessoalmente com a questão cicloviária (E6; E8; E10), como também atores da sociedade civil que buscavam acesso individual às instituições públicas (E1; E7; E4).

Em 2006 o projeto, que naquela altura se chamava Grupo de Trabalho Pró-Ciclista, já havia ganhado visibilidade após o êxito inicial na busca por investimentos internacionais para desenvolver a primeira fase de um projeto executivo de rede cicloviária para a cidade de São Paulo, financiado com recursos do Banco Mundial (E6; E10). Em 2009, a partir de esforços dos atores envolvidos nos debates cicloviários estatais e não estatais vinculados ao cicloativismo, houve um movimento de mudança de arena (Baumgartner e Jones, 1993, p. 32), que visava aproximar a agenda cicloviária da arena decisória responsável por lidar com as questões de deslocamentos urbanos (E5; E6; E8; E9; E10), transferindo institucionalmente a gestão do GT da SVMA para a Secretária Municipal de Transportes. Tal mudança teve um duplo impacto sobre o processo: por um lado, insulou a questão em um espaço pouco participativo, por outro, fortaleceu a rede temática da bicicleta, que passou a atuar de maneira organizada e 
sistematizada tanto em outras arenas públicas, aumentando a presença na Câmara Municipal, como também fora das estruturas estatais, em associações sociais, think tanks e organizações internacionais (E5; E9), culminando na terceira geração da participação. A participação institucionalizou-se, sobretudo, com a criação de Associação de Ciclistas Urbanos da Cidade de São Paulo (Ciclocidade). ${ }^{11}$ Uma das iniciativas mais relevantes que surgiram entre 2009 e 2012 foi a implementação da ciclofaixa de lazer, que contou com a participação do movimento cicloativista em parceria com think tanks, como o Institute of Transportation and Development Policies (E4), e as bicicletas compartilhadas, uma vez que ambas tiveram um papel pedagógico fundamental, pois possibilitaram os primeiros contatos de muitos cidadãos com a bicicleta urbana (E12).

Entre 2005 e 2012, a rede de cicloativistas que havia começado a se articular no interior da SVMA passou a se inserir em outros espaços institucionais. Destaca-se, nesse momento, a atuação do então vereador Chico Macena (PT) (2005-2012) e de sua equipe de trabalho, um grupo de especialistas e técnicos, composto por alguns atores vinculados à rede de cicloativistas, que passou a tratar a questão já nas discussões do Plano Diretor Estratégico (lei n. 13.430/2002) durante a gestão de Marta Suplicy (E5). A inserção desse grupo na discussão trouxe alguma visibilidade para o tema e começou a atrair alguns simpatizantes. Alguns atores mais experientes do cicloativismo, ainda muito incipiente, tinham algum know-how de planejamento cicloviário e começaram a dar consultorias, muitas vezes de forma proativa (E12). Nos planos regionais, algumas subprefeituras apresentaram alguns projetos que pensavam a bicicleta inserida na rede de mobilidade de maneira mais sistêmica. Da experiência dos atores envolvidos e dos resultados dos planos regionais, surgiu o capítulo sobre bicicleta do Plano Municipal de Circulação Viária e de Transportes. Já havia uma "coalizão de defesa" se formando para promover as ideias de políticas para bicicletas, mas, no primeiro PDE, a disputa foi vencida pelo grupo que defendia o foco no fluxo de automóveis. As propostas que surgiram traziam soluções para a melhora do tráfico de automóveis individuais, atendendo à demanda de grupos sociais mais articulados e mobilizados naquele momento. Contudo, a parte referente à bicicleta contida no plano, que tinha contribuições importantes dos planos regionais, serviu de base para a lei n. 14.266/2007, que instituiu o Sistema Cicloviário Municipal (E12).

Entre 2008 e 2012, o insulamento do tema na SMT acabou criando um vácuo na participação social formal que, apesar de esparsa, ocorria de forma concertada nos espaços de trabalho da SVMA. Essa mudança teve dois impactos: estabeleceu alguns espaços de discussão internos, como a criação do Departamento de Planejamento, Estudos e Projetos Cicloviários - DCL, e forçou a organização de atores sociais que foram excluídos da discussão. Para voltar a participarem, esses atores tiverem que se estruturar em torno de associações sociais. Passaram a atuar de maneira mais consistente, estratégica e estruturada, falando não mais como cicloativistas independentes, mas como representantes de coletivos (E12). A articulação desses atores possibilitou uma nova estratégia de participação, mais organizada e combativa, como demonstra a atuação da Ciclocidade, que participou ativamente de 
diversas políticas públicas como a ciclofaixa de lazer e produziu estudos autônomos. Foi desse grupo de ação, que envolvia distintos atores e iniciativas, que surgiu a carta de compromisso assinada por quase todos os candidatos à prefeitura em 2012 (E4). A carta garantia a responsabilidade da construção de uma rede cicloviária de mais de 400 km, o que acabou forçando a entrada do tema nas propostas dos candidatos à na eleição municipal de 2012.

A SVMA foi o eixo de articulação da rede de especialistas e ativistas das políticas cicloviárias em São Paulo que atuaria no período em parceria com a prefeitura. A interação dos atores ocorria por meio de arranjos abertos e heterogêneos, em uma rede temática de políticas públicas (Massardier, 2006), pautada pelo objetivo comum de inserir a bicicleta no sistema de mobilidade. Algumas ações, como as ciclofaixas de lazer e as bicicletas, contaram com maior envolvimento de atores externos ao Estado, iniciativa privada e sociedade civil organizada. A infraestrutura não se desenvolveu, no entanto, devido à falta de uma proposta alternativa à complexa e cara infraestrutura segregada, que vinha sendo desenvolvida pelos técnicos e especialistas, e à ausência de recursos consistentes e estáveis para o desenvolvimento de projetos ambiciosos (E9).

Em 2012, Fernando Haddad (PT - Partido dos Trabalhadores) foi eleito com uma proposta que prometia mudanças urbanas significativas para a cidade. Em seu plano de governo, Haddad despontava como um provável defensor da agenda cicloviária. Mesmo diante das contingências financeiras de crise e do agravamento da instabilidade política que marcou sua gestão, foi totalmente aderente à proposta do sistema cicloviário de 400 km elaborada pela equipe do gabinete do vereador Chico Macena (PT), que seria convidado, pelo prefeito, para ser o Secretário Municipal de Governo entre 2013-2016. Macena foi determinante para a indicação de atores como Suzana Nogueira e Ronaldo Tonobohn (E5; E10; E12), que já participavam como ativistas das ações do projeto ciclista (SVMA) nos anos 1990. Naquele momento, passaram a coordenar as ações como mediadores e membros da comunidade epistêmica da ciclomobilidade urbana, compartilhando seus conhecimentos sobre o tema e buscando construir consensos internos na Prefeitura para garantir a execução da agenda cicloviária (E5; E10; E11; E12).

Além de dar espaço para atores destacados e experientes, Haddad ainda teve um papel destacado como empreendedor de políticas públicas, $^{12}$ nos sentido proposto por Kingdon (2003), na proposição de uma solução que permitiu a criação da extensa rede cicloviária que se configurou na cidade a partir de 2014 (Leite, Cruz e Rosin, 2018). Em uma viagem oficial a Buenos Aires, o então prefeito teve um contato fortuito com as Bicisendas ${ }^{13}$ enquanto realizava um deslocamento pela cidade. Diante da baixa complexidade das vias (que ocupavam majoritariamente vagas de carros e eram segregadas, sobretudo, por sinalização horizontal), Haddad vislumbrou a possibilidade de implementar os 400 quilômetros de vias prometidos em seu plano de governo a baixo custo e com rapidez, tirando o espaço do carro e evitando obras complexas, caras e demoradas (E5; E7; E10; E11). Haddad teve a habilidade de visualizar a ideia implementada em Buenos Aires e tentar adaptá-la ao contexto paulistano. Apesar de não haver estabelecido uma cooperação formal entre as prefeituras, Haddad orientou o então 
Secretário dos Transportes, Jilmar Tatto, a conhecer a solução, para, em seguida, adaptá-la e implementá-la à realidade paulistana.

0 conhecimento e a experiência de alguns atores individuais foram determinantes para a criação de uma nova estratégia de implementação. A formulação da nova proposta de sistema cicloviário, composta em grande parte por ciclofaixas de baixa complexidade, levou em consideração inspirações e experiências de Nogueira, Boney e Tonobohn (entre outros), assim como de atores mais distantes da implementação direta, como o prefeito Haddad (E12). 0 contexto político favorável possibilitou a inserção das ideias de políticas cicloviárias que vinham sendo gestadas, ao longo dos anos, no interior da SVMA, nas atividades da Câmara, da SVMA, da CET e do Cicloativismo em geral (E4; E5; E7; E8; E10; E12). A partir de 2013, a participação social ganhou novos significados para a consecução da agenda de ciclomobilidade. Na esteira das manifestações de junho de 2013, a reativação do Conselho Municipal de Transportes e Trânsito garantiu o aumento da influência de grupos externos ao estado. A participação da sociedade civil passa a ser mais formal e menos condicionada pela rede de ação do cicloativismo, recebendo, assim, novos atores da sociedade civil (E10).

A partir da implementação da rede cicloviária na gestão Haddad, complementada com a reativação do CMTT e da criação da câmera temática da bicicleta, houve a formação do que se denomina aqui a quarta geração do cicloativismo. Se, em um primeiro momento, o conselho foi ocupado por lideranças das gerações anteriores, após 2016, a participação passa a ser mais heterogênea e capilarizada, com eleições de conselheiras e conselheiros de regiões centrais e periféricas, bem como com novas associações e iniciativas, tanto da sociedade civil como da iniciativa privada, a qual vem sendo representada pelo interesse renovado do Banco Itaú nas bicicletas compartilhadas ${ }^{14}$ e o sistema de bicicletas dockless proposto pela empresa Yellow. No entanto, ainda que os atores sigam inseridos nas instituições e arenas políticas, a incompatibilidade com o discurso da Gestão Dória/Covas (2017-2020) inviabilizou avanços na agenda, gerando uma recomposição da participação, que agora se organiza para defender a manutenção da infraestrutura cicloviária na intenção de conter os retrocessos anunciados pela gestão. Se, no momento anterior, a participação esteve mais relacionada com a implementação da nova agenda, agora se concentra em resistir à negação da atual rede cicloviária. Ações desenvolvidas pela Ciclocidade, como a Auditoria Cidadã da Infraestrutura Cicloviária (Nogueira et al., 2018), procuram criar elementos de advocacy para frear a retomada do discurso rodoviarista do "Acelera SP". ${ }^{15}$

\section{Considerações finais}

São Paulo é uma megalópole complexa, e seu território foi profundamente marcado historicamente pela segregação do espaço urbano e pela mobilidade urbana configurada pelos interesses rodoviaristas. Nesse sentido, a inserção da bicicleta como modal alternativo de transporte representa um elemento de tensão à lógica privatista e individualista ligada ao símbolo do automóvel. Neste texto, procurou-se discutir o processo político que tem marcado os avanços de movimentos de contradição 


\section{Imagem 1 - Trajetória cronológica da agenda cicloviária \\ e a evolução do "cicloativismo" em São Paulo - 1975-2016}

\section{Sequência cronológica dos marcos institucionais da agenda cicloviária}

Bicicleta passa timidamente pela agenda pública durante gestão municipal de Setúbal (1975-79) em função da crise do petróleo.

Pró-alcool e as gestões Maluf e Quadros bicicleta desaparece da pauta governamental

Aprovação da lei municipal no 10.907/1990, pelo vereador Walter Feldman

Criação do Grupo Ciclista no bojo da Secretária do Verde e do Meio Ambiente

Primeiras ciclovias implementadas aproximadamente $30 \mathrm{Kms}$, majoritariamente em parques

A bicicleta entra marginalmente na discussão do plano diretor estratégico de 2001-04.

Grupo ciclista vira GT Pró-Ciclista. Além de projetos e diagnósticos, o GT desenvolve a implementação da ciclovia do Pq. Linear Zilda Arns com apoio do Banco Mundial

Aprovação da lei 14.266/2007(institui o sistema cicloviário), aprovada pelo vereador Chico Macena

Implementação da ciclofaixa operacional (de lazer)

Implementação de aproximadamente $40 \mathrm{kms}$ de ciclovias com apoio do governo do Estado (Metro, CPTM e SABESP)

Primeiro contrato de cessão para implementação do sistema de bicicletas compartilhadas operado pelo banco Itau

Entrada na agenda decisional: proposta de rede cicloviária de $400 \mathrm{Kms}$ é inserido no plano de metas da gestão Haddad

Criação do CMTT e da camara temática da bicicleta

Implementação de 400 kms de infraestrutura cicloviária, majoritariamente ciclofaixas de baixa complexidade

\section{Gerações do cicloativismo}

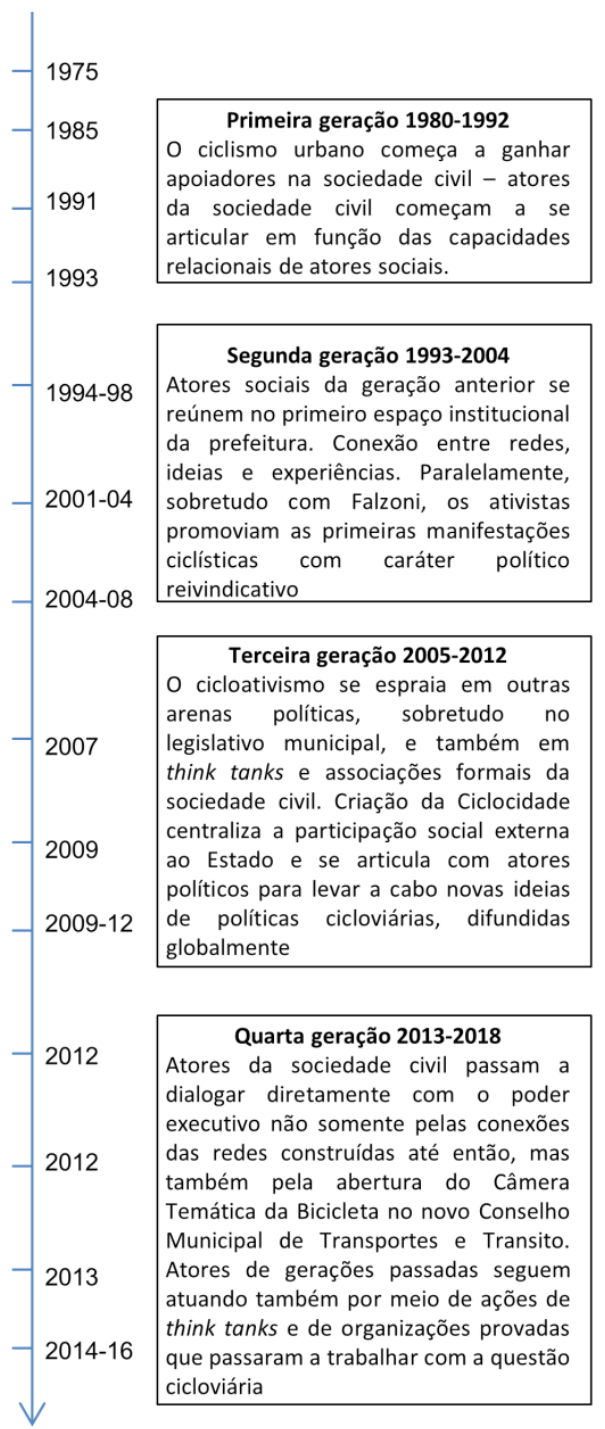

Fonte: elaborado pelos autores. 
e conflito diante da hegemonia do paradigma rodoviarista na mobilidade urbana das cidades brasileiras. Não se trata de um fenômeno estritamente nacional. Vários países têm discutido, há décadas, modais alternativos de transporte que democratizem o acesso ao espaço público e produzam menores pegadas ecológicas. Vale dizer, em contexto contemporâneo marcado por sucessivas crises do que Streeck (2012) denomina "capitalismo democrático", ou seja, relações disfuncionais entre políticas democráticas e mercados capitalistas com marcante viés financeiro e privado às expensas da lógica pública. Diante da hegemonia e do monopólio dos interesses do capital, os processos políticos têm mostrado que há fendas e contradições a serem exploradas.

0 olhar para o movimento e a circulação de ideias e atores sociais e políticos, individuais e coletivos, é um caminho analítico profícuo para a discussão dos processos de resistência que podem não ser evidenciados a partir de lentes teóricas estruturalistas e macroestruturas. Por meio da mobilização das categorias analíticas das políticas públicas, partindo do pressuposto de que 0 ataque às dimensões coletivas e públicas é longevo, mas que se intensificou com o fortalecimento da ordem neoliberal em escala internacional, desenvolveu-se, neste texto, a ideia de que o ativismo ciclista, ou cicloviário, foi um movimento político de resistência, no campo de disputa da mobilidade urbana em São Paulo, que ganhou envergadura no tempo e na prática política travada entre vários atores e arenas institucionais.

A escolha metodológica do process tracing permitiu elaborar uma narrativa explicativa cujo eixo é o traço do caminho, a rota de ação não previamente determinada dos atores ativistas, mas construída no processo político que se configurou em meio a disputas e enfrentamentos de contingências e incertezas. Os atores se movimentaram dentro e fora de estruturas governamentais, acumulando aprendizados (Hall, 1993), incorporando novas ideias, mais apoios e mais complexidade em termos de representação, como demonstra a sucessão de gerações de cicloativismo proposta.

Há três elementos interdependentes a se destacar enquanto resultados desta discussão, que se estruturam a partir da proposta analítica de Kingdon (2003): o fluxo de problemas que configura o contexto e os elementos contingenciais da possibilidade de mudança de agenda (as manifestações de 2013); o fluxo de soluções que envolve os atores e as ideias em movimento de disputa e conflito (o ativismo cicloviário); e o fluxo político, a dinâmica política de embate dos atores que potencialmente podem gerar o motor da mudança. No caso deste texto, destacam-se os elementos da eleição de um novo governo e a ação de grupos de pressão que atravessam a formação da agenda de governo do grupo político recém-eleito à época (2012).

0 ciclo de vida e de amadurecimento político da rede do ciclismo urbano em São Paulo envolveu uma trajetória política de embates, articulação e persuasão bastante dinâmica. Os atores movimentavam-se na sociedade civil e no governo, circulando entre diferentes arenas e acumulando aprendizado social (ibid.) no tempo. No entanto, as etapas de inserção institucional, sem dúvida, marcaram a configuração de redes esparsas de atores em torno da bicicleta, alçando-as a movimentos sociais politicamente organizados, que passaram a agir como comunidades epistêmicas, nos termos de 
Haas (1992) na Secretaria do Verde e Meio Ambiente (SVMA). Naquele lugar institucional, as ações como atores políticos tornaram-se mais complexas e mais específicas no sentido da elaboração de um projeto de implementação da estrutura viária para as bicicletas. Legitimados pelo diagnóstico da bicicleta como meio de transporte mais sustentável, os grupos articulavam novos atores (especialistas e apoiadores políticos) e discutiam instrumentos com alto potencial de conflito urbano, como vias estruturais de alta complexidade do sistema cicloviário. Da SVMA, a articulação capilarizou-se em novas arenas, como no Legislativo Municipal e em organizações não governamentais e think tanks. Pode-se dizer que a rede de atores ganha traços de coalizão de defesa (Sabatier, 2007) ao se tornar mais complexa com relação à forma de atuação política. Não se trata mais de compartilharem somente uma visão de mundo ou a "paixão" pela bicicleta, mas de um trabalho de debates em torno de ideias sobre desenhos de programas e planejamento de estratégias políticas para que a política cicloviária caminhe politicamente e seja implementada.

0 trânsito do grupo de cicloativistas da SVMA para a Secretaria Municipal de Transportes (SMT) foi um ponto de inflexão no processo. Tratou-se de arena mais favorável, com mais formalização e possibilidade de inserção dos atores em estruturas institucionais de representação de interesses, como as câmaras e conselhos vinculadas à SMT. No mesmo período, ocorreram dois elementos fundamentais que, conjuntamente à ação do ativismo, operaram no sentido de abrir a janela de oportunidade para que a política cicloviária fosse implementada: a vitória de Fernando Haddad (Partido dos Trabalhadores) na eleição municipal de
2012 e o ciclo polifônico de manifestações de 2013, com destaque para a atuação do MPL (Movimento Passe Livre). ${ }^{16}$

Como discutido anteriormente, a eleição de Fernando Haddad representou, no campo das políticas públicas, inclusive nas de mobilidade urbana, a chance de se discutir, no plano governamental, ideias de planejamento do espaço urbano para além da lógica do capital. Sem dúvida, houve contradições em que os interesses da financeirização ganharam os embates políticos, como no caso das políticas de habitação. ${ }^{17}$ No entanto, a implementação da política cicloviária representou o estabelecimento do confronto com estruturas políticas e sociais profundamente identificadas com valores conservadores e conectados às classes sociais mais abastadas e motorizadas individualmente. Fortemente pressionado pelos grupos atuantes nas manifestações de 2013, sobretudo o MPL, o governo Haddad encampou o projeto do grupo de cicloativistas que circulava na SMT. A proposta de implementação das faixas exclusivas de ônibus e da infraestrutura cicloviária foi a resposta política possível do governo municipal, premido por uma grave crise financeira no início do mandato. No caso específico da bicicleta, tratou-se de uma proposta totalmente aderente às ideias que circulavam no governo sobre direito à cidade e democratização dos espaços públicos. A ressignificação criada com a interdição da avenida Paulista aos domingos é um exemplo claro desse processo, que permanece no atual governo, que se caracteriza por uma base social e política de apoio bastante diversa do anterior.

É interessante destacar que a convergência do cicloativismo com o grupo político que alçou o poder municipal em 2012 em São 
Paulo provocou profundas tensões sociais e políticas ao promoverem a bicicleta a meio de transporte na cidade, disputando o espaço público com automóveis, ônibus e motos. Leite, Feijó e Rosin (2018) demonstraram a ostensiva reação negativa dos órgãos da grande mídia, Folha de S.Paulo e, sobretudo, O Estado de S.Paulo, analisando os editoriais dos respectivos veículos no período. Não houve registro de editoriais que promovessem a discussão epistêmica e política internacional sobre a bicicleta como meio de transporte, a despeito de inúmeros estudos científicos sobre o tema. Também não houve textos de opinião com viés positivo. Os autores analisaram diferentes argumentos que tinham a clara intenção de criar um sentimento público negativo em torno da "novidade" da bicicleta. Tratou-se de um pesado jogo político de construção de narrativa contra os interesses cicloviários, apelando invariavelmente para o direito de ir e vir do carro no meio urbano.

Enfim, trata-se de uma disputa ainda aberta e em construção. Se a bicicleta surge no horizonte como elemento de resistência, passa a ser incorporada à lógica da mercantilização das relações de transporte, por meio de empresas e bancos que vislumbram as oportunidades de negócio. ${ }^{18}$ Esse processo pode enfraquecer o potencial de resistência da bicicleta à ordem neoliberal na cidade, no capítulo da mobilidade urbana. Contudo, vale acompanhar, em se tratando de questões complexas e dinâmicas, eivadas em contradições.

[I] https://orcid.org/0000-0003-0321-2984..

Universidade de São Paulo, Escola de Artes, Ciências e Humanidades, Programa de Pós-Graduação em Gestão de Políticas Públicas. São Paulo, SP/Brasil.

lucas.rosin@usp.br

\section{[II] https://orcid.org/0000-0002-4610-0520}

Universidade de São Paulo, Escola de Artes, Ciências e Humanidades, Programa de Pós-Graduação Mudança Social e Participação Política. São Paulo, SP/Brasil.

criskerches@gmail.com 


\section{Notas}

(1) Reitera-se que o objetivo deste texto é discutir a bicicleta como elemento de resistência ao paradigma rodoviarista. $\mathrm{O}$ contexto neoliberal de mercadorização e financeirização do espaço urbano, nos termos de Harvey (2014), é um elemento importante na composição do problema, mas não é o foco central da análise.

(2) Maia foi prefeito nos períodos 1938-1945 e 1961-1965. Maluf foi prefeito nos períodos 1969-1971 e 1993-1997 e governador entre 1979-1982. Também foi Secretário Estadual dos Transportes entre 1971-1975. Quadros foi prefeito nos períodos 1953-1955 e 1986-1989 e governador entre 1955-1959.

(3) Como aponta Tavolari (2016), o conceito, que remonta à obra clássica de Henri Lefebvre publicada em 1968, e foi discutido também por Harvey e Castells à época, volta a ganhar força em 2008, com a releitura do próprio Harvey em contexto de múltiplas crises do capitalismo, onde floresce uma sociedade civil "rebelde" que resiste aos processos de mercantilização das cidades. Ainda segundo Tavolari (ibid.), o conceito vem sendo utilizado na América do Sul em geral, de forma adaptada por grupos epistêmicos, muitas vezes de maneira implícita e reivindicativa por movimentos sociais. No Brasil, o conceito tem uma trajetória particular. Em termos acadêmicos, a tradução quase que simultânea para o português da obra de Lefebvre permitiu que pesquisadores do campo do urbanismo como Maricato e Jacib tivessem acesso ao conteúdo já nos anos 1970, e em trabalhos de Bonduki e Sader na década seguinte. Nos movimentos sociais, o conceito é usado de forma menos "romantizada", enfatizando seu caráter reivindicativo no acesso democrático aos equipamentos públicos e espaços urbanos (ibid.).

(4) Para um debate mais aprofundado e atualizado, ver Cunha e Araújo (2018).

(5) Para uma explicação mais detalhada sobre o uso de entrevistas e suas técnicas subjacentes na operacionalização do process tracing, ver Porto de Oliveira (2016).

(6) Para mais detalhes, ver Tomazini e Leite (2016) e Tomazini (2018).

(7) Lemos (2018) apresentou trabalho muito interessante que organiza a participação social no caso de São Paulo em gerações discursivas. Aqui, tentamos aproximar essa ideia de gerações de participação ao debate do policy process, destacando os tipos de atores que participam do processo, bem como os arranjos interacionais que articulam esses participantes, entendidos como partes necessárias de mecanismos causais mais amplos.

(8) Responsável pela lei n. 10.907, de 1991, que "dispõe sobre a destinação de espaços para ciclovias no município de São Paulo, e dá outras providências". Em teoria, a lei exigia que a construção de novas avenidas na cidade incluísse infraestrutura cicloviária. Na prática, o dispositivo teve efeito quase nulo. Vale destacar que Feldman foi responsável por solicitar alguns estudos cicloviários junto à CET nos anos 1980, que também era estimulada a produzir estudos por orientação de técnicos vinculados ao Giepot no ministério dos transportes (Malatesta, 2012).

(9) Optamos por usar a nomenclatura de E1 a E11 para citar os entrevistados de modo a melhorar a fluidez do texto. No entanto, todos estão identificados no final da seção das referências bibliográficas.

(10) Durante sua gestão municipal, entre 1993 e 1996, Maluf esteve filiado inicialmente ao Partido Democrático Social. Em seguida passou a compor uma fração "dissidente" no Partido Progressista Reformador e, em 1995, migrou para o Partido Progressista Brasileiro (PPB). 
(11) Alguns outros movimentos organizados surgiram no mesmo período, como CicloBR, entre outros. A rede seguiu expandindo-se com a institucionalização de diversos movimentos locais como o Bike Zona Sul, além de outras organizações como o Bike Anjo, Vá de bike (iniciativa de Renata Falzoni).

(12) Consagrado no modelo kingdoniano, o empreendedor é um ator central para explicar processos de formação de novas agendas. Tal ator se configura como um defensor de certas ideias, que têm habilidade (capacidades políticas, relacionais, discursivas) de unir os fluxos (política, de problemas e soluções) durante uma janela de oportunidades (Capella, 2016).

(13) Nome em espanhol da infraestrutura cicloviária utilizada em Buenos Aires, que se assemelha ao modelo de ciclofaixa utilizado em São Paulo. Ainda que contenha variações, esse tipo de infraestrutura se destaca por estar inserido no sistema viário segregado, sobretudo, por elementos de sinalização horizontal, vertical e semafórica (Bianco, 2003)

(14) A parceria que surgiu no final da gestão Kassab, e foi aprimorada com caráter social na gestão Haddad, tomou um rumo mais mercantil na gestão Dória/Covas. A “desregulação” das regras permitiu com que o banco retirasse estações não lucrativas, sobretudo as que haviam sido instaladas em regiões mais distantes do centro, e concentrasse a operação em regiões de maior lucratividade. O mesmo vem ocorrendo na implementação do sistema dockless.

(15) Slogan de Campanha de João Dória em 2016, criado a partir do discurso crítico à redução das velocidades nas vias da cidade, promovida pela gestão Haddad.

(16) Há literatura profusa sobre as manifestações de 2013. Referência acadêmica recente que pode ser consultada: Alonso (2017).

(17) Sobre a problemática habitacional no município e no estado de São Paulo, ver: Siqueira (2014); Nakano (2018); e Pereira e Palladini (2018).

(18) Exemplos recentes dizem respeito à concessão da operação de sistemas de bicicletas compartilhadas. Atualmente, os sistemas operam livremente em função da lucratividade da operação. Apesar de alguns tímidos esforços, esses sistemas estão instalados tão somente em regiões nobres do centro-oeste de São Paulo.

\section{Referências}

ALONSO, A. (2017). A política das ruas: protestos em São Paulo de Dilma a Temer. Novos Estudos Cebrap, v. esp. Dinâmicas da Crise, pp. 48-59.

BAUMGARTNER, F. R. e JONES, B. D. (1993). Agendas and instability in American politics. Chicago, University of Chicago Press.

BEACH, D. e PEDERSEN, R. B. (2013). “Developing empirical tests of causal mechanisms”. In: BEACH, D. e PEDERSEN, R. B. Process-tracing methods: foundations and guidelines. Ann Arbor, The University of Michigan Press.

BIANCO, S. (2003). O papel da bicicleta para a mobilidade urbana e a inclusão social. Revista dos Transportes Públicos - ANTP - Ano 25, 3o trimestre. 
CAMPBELL, J. L. (1998). Institutional analysis and the role of ideas in political economy. Theory and society, v. 27, n. 3, pp. 377-409.

CAPELLA, A. C. N. (2016). Um estudo sobre o conceito de empreendedor de políticas públicas: Ideias, Interesses e Mudanças. Cadernos EBAPE.BR (FGV), v. 14, pp. 486-505.

CAPELLA, A. C. N e BRASIL, F. G. (2015). Análise de Políticas Públicas: uma revisão da literatura sobre o papel dos subsistemas, comunidades e redes. Novos estudos CEBRAP (on-line), v. 101, pp. 57-76.

CUNHA, E. S. e ARAÚJO, C. M. L. (2018). Process tracing nas Ciências Sociais: fundamentos e aplicabilidade. Brasília, Enap.

ELIAS, N. (1993). O processo civilizador. Vol. II: Formação do estado e civilização. Rio de Janeiro, Zahar.

HAAS, P. M. (1992). Introduction: Epistemic Communities and International Policy Coordination. International Organization, v. 46, n. 1, pp. 1-35.

HALL, P. A. (1993). Policy Paradigms, Social Learning, and the State: The Case of Economic Policymaking in Britain. Comparative Politics, v. 25, n. 3, pp. 275-296.

HARVEY, D. (2014). Cidades rebeldes: do direito à cidade à revolução urbana. São Paulo, Martins Fontes.

HOBSBAWM, E. (2007). Era dos extremos. O breve século XX: 1914-1991. São Paulo, Companhia das Letras.

KINGDON, J. (2003). Agendas, alternatives, and public policies. Nova York, Harper Collins.

LARA, F. L. (2016). “A arquitetura moderna brasileira e o automóvel: o casamento perfeito". In: BALBIM, R., KRAUSE, C. e LINKE, C. C. (orgs.). Cidade e movimento: mobilidades e interações no desenvolvimento urbano. Brasília, Ipea, ITDP.

LEITE, C. K. S.; CRUZ, M. F. e ROSIN, L. B. (2018). Difusão da política cicloviária no município de São Paulo: resistências, apoios e o papel da mídia. Revista de Administração Pública RAP. Rio de Janeiro, v. 52, n. 2, pp. 244-263.

LEITE, C. K. S. e PERES, U. D. (2015). Paradigmas de desenvolvimento e disseminação de políticas: raízes locais da criação do Programa Bolsa Família. Organizações \& Sociedade. Salvador, v. 22, n. 75, pp. 621-638.

LEMOS, L. L. (2018). Cycling in São Paulo: pro-bike activism as a key for pro-bike policies. Velo-city S4C-Rio de Janeiro. Disponível em: https://ecf.com/velo-city/velo-city-2018-rio-de-janeiro/velocity-2018-presentations. Acesso em: 28 jan 2019.

MALATESTA, M. E. B. (2012). A história dos estudos de bicicletas na CET. Boletim Técnico da CET, 50. Companhia de Engenharia de Tráfego. São Paulo.

MARQUES, E. (2012). "Introdução”. In: MARQUES, E. (org.). Redes sociais no Brasil: sociabilidade, organizações civis e políticas públicas. São Paulo, Centro de Estudos da Metrópole, Editora Fino Traço.

MASSADIER, G. (2006). “Redes de política pública”. In: SARAVIA, E. e FERRAREZI, E. Políticas Públicas Coletânea, Volume 2. Brasília, Enap.

MILANI, C. R. S. (2008). O princípio da participação social na gestão de políticas públicas locais: uma análise de experiências latino-americanas e europeias. Revista de Administração Pública, v. 42, n.3, pp. 551-579. 
NAKANO, A. K. (2018). Desigualdades habitacionais no "repovoamento" do centro expandido do município de São Paulo. Cadernos Metrópole. São Paulo, v. 20, n. 41, pp. 53-74.

NOGUEIRA, S. L. et al. (2018). Auditoria Cidadã da Infraestrutura Cicloviária da Cidade de São Paulo. Ciclocidade. Associação dos Ciclistas Urbanos da Cidade de São Paulo.

ONU HABITAT (2017). "Planeamiento Urbano para Autoridades Locales. Disponível em: https:// unhabitat.org/books/planeamiento-urbano-para-autoridades-locales/. Acesso em: 15 dez 2018.

PEREIRA, A. L. S. e PALLADINI, G. M. (2018). Parceria público-privada para construção de moradia popular: fundamentos institucionais para a expansão do mercado de habitação em São Paulo. Cadernos Metrópole. São Paulo, v. 20, n. 43, pp. 879-903.

POLANYI, K. (2000). A grande transformação: as origens da nossa época. Rio de Janeiro, Campus.

POLANYI-LEVITT, K. (2014). Los conceptos más importantes en el trabajo de Karl Polanyi y su relevancia contemporánea. Economía y Desarrollo, v. 151, n. 1, pp. 198-211.

PORTO DE OLIVEIRA, O. (2016). Embaixadores da participação: A difusão internacional do Orçamento Participativo a partir do Brasil. São Paulo, Annablume.

REIS, E. P. (2015). Sociologia política e processos macro-históricos. Sociologias. Porto Alegre, v. 17, n. 38, pp. 18-43.

REQUENA, C. (2015). O paradigma da fluidez do automóvel: burocracias estatais e mobilidade em São Paulo. Dissertação de Mestrado. São Paulo, Universidade de São Paulo.

ROLNIK, R. e KLINTOWITZ, D. (2011). Mobilidade na cidade de São Paulo. Estudos Avançados. São Paulo, v. 25, n. 71, pp. 89-108.

ROSIN, L. R. (2018). A formação das agendas de políticas cicloviárias em Bogotá, Buenos Aires e São Paulo: uma análise exploratória sobre arranjos interacionais e atores estratégicos. Agenda Política. São Carlos, v. 6, pp. 240-273.

SABATIER, P. (2007). "The need for better theories". In: SABATIER, P. (ed.). Theories of the policy process. Westview, Second Edition.

SCHNEIDER, S. e ESCHER, F. (2011). A contribuição de Karl Polanyi para a sociologia do desenvolvimento rural. Sociologias, v. 13, n. 27, pp. 180-219.

SCHOR, T. (1999). O automóvel e o desgaste social. São Paulo em Perspectiva. São Paulo, v. 13, n. 3, pp. 107-116.

SIQUEIRA, M. T. (2014). Entre o fundamental e o contingente: dimensões da gentrificação contemporânea nas operações urbanas em São Paulo. Cadernos Metrópole. São Paulo, v. 16, n. 32, pp. 391-416.

STREECK, W. (2012). As crises do capitalismo democrático. Novos estudos - Cebrap. São Paulo, n. 92, pp. 35-56.

TAVOLARI, B. M. D. (2016). Direito à cidade: uma trajetória conceitual. Novos Estudos Cebrap, v. 104, pp. 93-109.

TOMAZINI, C. G. (2018). As análises cognitivas de políticas públicas: uma agenda de pesquisa. Política Hoje, UFPE, v. 27, pp. 1-25,

TOMAZINI, C. G. e LEITE, C. K. S. (2016). Programa Fome Zero e o paradigma da segurança alimentar: ascensão e queda de uma coalizão? Revista de Sociologia e Política, Curitiba, v. 24, n. 58, pp. 13-30. 
VASCONCELLOS, E. A. (2013). Políticas de transporte no Brasil: a construção da mobilidade excludente. São Paulo, Manole.

XAVIER, G. N. A. (2007). O cicloativismo no Brasil e a produção da lei de política nacional de mobilidade urbana. Revista Eletrônica dos Pós-Graduandos em Sociologia Política da UFSC, v. 3, n. 2, pp. 122-145.

(2011). O desenvolvimento e a inserção da bicicleta na política de mobilidade urbana brasileira. Tese de Doutorado. Florianópolis, Universidade Federal de Santa Catarina.

\section{Apêndice: lista de entrevistados}

(E1) ALCORTA, Arturo: cicloativista de longa data, foi criador do "Bike Repórter Rádio Eldorado FM" (SP). Entrevista realizada no dia 29/6/2016, em São Paulo-SP.

(E2) ARANHA, Carlos: cicloativista e especialista em mobilidade urbana, integrante do Conselho Municipal de Política Urbana, e coordenador do GT Mobilidade da "Rede Nossa São Paulo". Entrevista realizada no dia 7/12/2015 em São Paulo-SP.

(E3) BANTEL, Gunther: engenheiro metalúrgico de formação, começou a trabalhar com questões de ciclomobilidade depois de viajar a Holanda na década de 1970. A entrevista com um dos mais importantes cicloativistas brasileiros foi realizada dentro de um carro (ironicamente), a caminho do aeroporto de Congonhas, no dia 7/12/2015, em São Paulo-SP.

(E4) BENICCHIO, Thiago: gerente de transportes ativos do ITDP Brasil. Cicloativista desde meados da década de 2000, é um dos fundadores da Associação de Ciclistas Urbanos da Cidade de São Paulo (Ciclocidade). Entrevista realizada no dia 3/12/2015, em São Paulo-SP.

(E5) "BONEY", Odair Henrique Neto: assessor especial de políticas públicas da Secretaria Municipal de Governo da prefeitura de São Paulo. Participou do desenvolvimento do Programa de Governo de Fernando Haddad, então candidato a prefeito. Entrevista realizada no dia 22/6/2016, em São Paulo-SP.

(E6) CENEVIVA, Laura L. V.: arquiteta e coordenadora do Grupo Executivo Pró-Ciclista desde sua criação até 2009. Entrevista realizada no dia 27/11/2015, em São Paulo-SP.

(E7) FALZONI, Renata: ativista social vinculada à ciclomobilidade desde os anos 1980. Também atua nos meios de comunicação, sempre associada à bicicleta. É idealizadora da organização Vá de Bike. Produziu e dirigiu recentemente o filme "O Brasil que pedala". Entrevista realizada no dia 4/3/2019, em São Paulo-SP.

(E8) HOFFMAN, Ana M.: funcionária de carreira da Secretaria do Verde e do Meio Ambiente desde 1994, acompanhou todas as atividades voltadas à ciclomobilidade. Entrevista realizada no dia 27/11/2015, em São Paulo-SP.

(E9) JORGE, Eduardo: médico sanitarista de longa trajetória política. Foi secretário do Verde e do Meio Ambiente entre 2005 e 2012. Entrevista realizada no dia 16/2/2016, em São Paulo-SP.

(E10) NOGUEIRA, Suzana L.: arquiteta e urbanista, foi coordenadora do Departamento de Planejamento Cicloviário da CET durante a segunda metade da gestão Haddad. Entrevista realizada no dia 17/2/2016, em São Paulo-SP. 
(E11) PAIVA, Reginaldo: engenheiro da CPTM, atua desde os anos 1980 como militante da questão cicloviária, tanto dentro das instituições, como funcionário de carreira, como coordenando projetos em instituições, como a Associação Nacional dos Transportes Públicos. Entrevista realizada em São Paulo, em 8/6/2016.

(E12) TONOBOHN, Ronaldo: foi superintendente de planejamento da CET durante a gestão Haddad. Trabalha com a questão cicloviária desde a década de 1990. Entrevista foi realizada no dia 11/8/2016, em São Paulo-SP.

Texto recebido em 15/mar/2019

Texto aprovado em 10/maio/2019 